\title{
Adriana Azucena Rodríguez: Permanente fugacidad. Ensayos sobre minificción. México: Universidad Autónoma Metropolitana, 2020.
}

Permanente fugacidad, de la autoría de la doctora Adriana Azucena Rodríguez, es una publicación pertinente y que avanza en los estudios de la minificción, al retomar y cuestionar temas que se podían considerar como materia ya sólida. Así, examina muy detenidamente y, cabe decir, revalora ciertos conceptos inherentes al género, como ya se explicará párrafos abajo. En la contraportada del libro se lee: "aún son escasos los volúmenes especializados en el tema, al menos en México, uno de los países que inauguraron la reflexión de las formas breves". Por su temática, Permanente fugacidad subsana esta necesidad de teorizar, sobre todo al tomar en cuenta que no se detiene en obras particulares, sino que, por el contrario, aborda temas generales y constantes del género, analiza sus características, y con una amplia bibliografía y textos minificcionales a manera de ejemplo de lo argumentado, profundiza y clarifica la configuración formal de la minificción. Así, elementos señalados en anteriores ocasiones como definitorios del género, tales como la ironía, o el humor mismo, la intertextualidad, el hecho de que el título sea de capital importancia, la tendencia a la máxima brevedad, así como la frecuente recurrencia a temas sobrenaturales en las tramas, son estudiados de manera rigurosa, para obtener notables conclusiones. Vayamos por partes.

La autora es doctora en Literatura Hispánica por el Centro de Estudios Lingüísticos y Literarios de El Colegio de México, y actualmente es profesora investigadora de tiempo completo en la Universidad Autónoma de la Ciudad de México, a la par que se desempeña como docente en la Facultad de Filosofía y Letras de la Universidad Nacional Autónoma de México. Ha publicado otro par de obras teóricas y de análisis literario, así como seis de cuento y minificción. El libro, publicado por la Universidad Autónoma Metropolitana, se divide en una introducción a su cargo, ocho ensayos, una "coda" (se trata de una minificción que define al género como si fuera un animal), un epílogo, que integra seis entrevistas con minificcionistas, y la correspondiente bibliografía. En la breve introducción, la autora habla de su doble faceta de investigadora y creadora, por lo cual menciona que "la creación ha sido también una investigación sobre esta forma literaria" (2020: 9), y explica cómo ha abordado la escritura en sus diversos libros. Además, hace un rápido recorrido histórico del género, y aprovecha para mencionar las características principales de este, las cuales integran el tema de estudio de estos ensayos.

En "Género, nomenclatura y brevedad", Rodríguez hace hincapié en el aspecto comunal: "los responsables de su nominación y caracterización [de la minificción] son los diferentes grupos que conforman su comunidad: escritores, editores y lectores” (2020: 13), además de críticos y teóricos. Cada grupo es examinado en cuanto a sus contribuciones e interacciones, para dejar en claro que todos aportan algo. Muy probablemente entre las contribuciones consignadas más remarcables se encuentra lo relativo a las secciones de revistas que contribuyeron a definir el género, en términos de extensión, así como a proponer nomenclaturas, en décadas pasadas (el primero de estos casos es la ya mencionada El cuento, de la cual se refiere que en el número 41 [1969] "la revista agregó lo que Edmundo Valadés llamó «Minificciones»” [2020: 15]), así como 
la puesta de relieve del papel de los antologadores, importante en la consolidación del género, al seleccionar y difundir materiales relevantes, lo cual se ejemplifica por medio de la evolución de las antologías, desde Cuentos breves y extraordinarios, de Adolfo Bioy Casares y Jorge Luis Borges, de 1955, hasta las actuales. Este primer ensayo condensa datos, características, títulos y nombres que sin duda resultan familiares para los lectores asiduos a la minificción y quienes profundizan en su estudio, sin embargo, compilar toda esa información en un solo texto convierte a este en una necesaria y puntual introducción, de elevado valor referencial y bibliográfico para los lectores neófitos en el tema, y aún para quienes ya se han sumergido en él con anterioridad.

El siguiente par de ensayos, "Mínimos personajes" y "Dónde y cuándo", abordan elementos generales de la narrativa, desde la perspectiva minificcional. En el primero, la autora menciona que el género "ha dado lugar a pocos personajes memorables" (2020: 27) y a partir de Algirdas Julien Greimas y la teoría relativa a la noción de actante, delimita el concepto (de personaje) en lo referente a la minificción, además de mencionar que este se ve configurado por "una serie de vacíos de información que caracterizan al género" (2020: 30), lo cual genera un conjunto de personajes posibles, mismos que pueden clasificarse y describirse por los recursos empleados en su constitución. Así, propone una tipología "adecuada, por su particularidad de soportar la brevedad del género" (2020: 34), ejemplificada con textos: genéricos, arquetipos, estereotipos, tipos, individuos (difíciles de hallar debido a la falta de espacio para desarrollarlos, a no ser "en libros con un mismo personaje presente en cada minificción" [2020: 33]), sobrenaturales tradicionales, intertextuales, irracionales y objetos inanimados, así como el individuo cotidiano. Después, enumera una serie de recursos de creación e incorporación de personajes en la minificción (como titular al texto con el nombre del personaje), hasta llegar al punto de hablar del personaje inexistente, concepto relacionado con formas experimentales de la minificción (estructuras ajenas a la narrativa: epitafios, recetas, anuncios de ocasión, etc.).

Por su lado, "Dónde y cuándo" aborda los elementos de tiempo y espacio, los cuales, como el personaje, solo se desarrollan de acuerdo a la intención que se quiera lograr con cada texto. Ambos elementos son examinados a profundidad: el tiempo es desglosado en los conceptos de duración, orden y fecha, se integra un listado de las "clases de escenarios" a partir de lo propuesto por Enrique Anderson Imbert, entendido escenario como la suma de espacio y tiempo, se analizan el espacio abstracto, el textualizado, metalingüístico y, a partir de Roland Barthes, se señala la construcción del ambiente por medio de la intertextualidad. También son mencionadas otras formas de representar el ambiente: los escenarios simbólicos, relacionados con una entidad abstracta representada, un símbolo o arquetipo, y por otro lado, por asociaciones, es decir que, gracias a "las formas de hablar y la alusión a los objetos, también es posible reconocer el tiempo y el lugar donde ocurren los acontecimientos" (2020: 46), así como casos de espacios más complejos, tales como el diegético iso-tópico o el bi-isotópico imposible, entre otros.

"Títulos y subtítulos" inicia con la mención de la variabilidad de posibilidades del título, desde su importancia capital, su ausencia o su rasgo como único elemento del texto, tal como en "Fantasma", de Guillermo Samperio. La autora recurre a varios autores para tratar diversas funciones: previas, simultáneas y posteriores a la lectura, las cuales son citadas y comentadas a partir de la jerarquización propuesta por Miguel Ángel de la Fuente González. La parte final del 
capítulo se dedica a los títulos de sección que aparecen en diversas antologías del género, dado su carácter organizacional y clasificatorio de grupos de textos.

"Intertextualidad y minificción" inicia con el argumento de que "resulta tentador suponer que [la intertextualidad] define al género", y cómo "hay inconvenientes en ese recurso que deberían plantearse" (2020: 59). La introducción al tema refiere los trabajos de Gérard Genette, a propósito de las diversas posibilidades de relación entre textos. Posteriormente, se apunta que si bien la intertextualidad no es exclusiva de la minificción, es indiscutible que funciona "como mecanismo para economizar palabras" (2020: 61), y se señala como procedimiento de la narrativa posmoderna, algo ya mencionado en estudios teóricos tempranos de la minificción, entre ellos, los de Dolores Koch y Francisca Noguerol. La autora vuelve a Genette para hablar de intertextualidad, o transtextualidad, así como el extenso listado de sus diversos niveles, los cuales aborda, como es protocolo en el libro, con ejemplos minificcionales. A estas categorías se agrega la “intratextualidad” o "intertextualidad interna”, característica que José Enrique Martínez Fernández señala como frecuente en la narrativa posmoderna, y que se advierte "cuando el mecanismo intertextual afecta a textos del propio autor", además, "la relación entre textos de un mismo autor ha llegado a establecer modos particulares de estructuración de «series» de textos que [...] interactúan al interior del volumen unitario, en formas genéricas novedosas: novela de fragmentos, minificciones integradas y ciclos de minificción" (2020: 74). Rodríguez cierra este ensayo con algunos listados, como uno sobre las "posibilidades de reconocimiento e interrelación con la reescritura del original y que determinarán la experiencia estética” (2020: 75).

En “¿Reiteración o economía verbal?”, la autora explica que los procedimientos relacionados con estos conceptos resultan opuestos a los de la intertextualidad, entendida esta, como ya se mencionó, como "mecanismo para economizar palabras". Comenta que la repetición de elementos resulta, a pesar de esa búsqueda constante de la brevedad en el género, frecuente en la minificción, "sobre todo en autores con cierta tendencia hacia la reflexión sobre la lengua, los efectos fónicos en combinación con los semánticos o el vínculo entre la poesía y la prosa narrativa breve" (2020: 77). Posteriormente, aborda el caso de las figuras retóricas como recurso frecuente en los textos minificcionales, en especial los más breves. Se destacan las figuras fonéticas basadas en la repetición y que afectan el sonido, entre ellas, la aliteración. Por otra parte, comenta de la anáfora que "en prosa narrativa breve deriva en el paralelismo [...] El uso de la repetición en la serie de enunciados favorece diversos efectos, principalmente, la fuerza expresiva y la cohesión del texto. Por eso es que el paralelismo es un recurso frecuente en minificción" (2020: 80). El paralelismo, además, "es un recurso natural de los listados", recurrentes en el género, y "resulta también un recurso para las profecías, las ceremonias, las leyes" (2020: 80). La autora también aborda otras figuras, como la anadiplosis y la onomatopeya, así como los recursos de la anáfora, la similicadencia, la paranomasia, el palíndromo, el pleonasmo, el epíteto, el polisíndeton o la interrogación retórica. Con respecto a la elipsis, inherente a la minificción, y que al omitir palabras opera de maneras opuestas a los procedimientos de reiteración abordados en este ensayo, la autora comenta que "[n]o obstante, no se debe soslayar que la repetición en la narrativa breve constituye otra herramienta de gran potencial expresivo empleada por muchos escritores que han encontrado un equilibrio entre una y otra [la elipsis] para sus fines artísticos [...]. Los recursos de la repetición 
no son, como podría pensarse, opuestos a la minificción, sino que son comunes y [...] aportan valores estéticos" (2020: 87).

“¿Chiste o minificción?” aborda una selección de procedimientos o recursos tomados como casi definitorios del género, los cuales se manifiestan en diversas estructuras lúdicas que la autora recopila y describe, por medio de un análisis que va de los mecanismos básicos a los más elaborados. De esta manera, aborda estructuras como la del chiste, la anécdota cómica, para luego tratar motivos risibles, la ironía, el absurdo, el humor negro, la parodia y la sátira. De este listado destaca lo referente a la ironía y su intensificación, el sarcasmo, pues se hace la necesaria explicación de que no todo tipo de humor es ironía, ni que el humor es constante en la minificción: al profundizar en el tema algunas definiciones genéricas resultan por tanto inexactas.

En "La aparición de lo sobrenatural", la autora remite a las antologías primigenias del género (Cuentos breves y extraordinarios, Manual de zoología fantástica, El libro de la imaginación), y refiere el contenido de las mismas, para señalar que tales obras "evidencian la predilección de esta forma narrativa por motivos relacionados con lo sobrenatural" (2020: 103), los cuales resultan aún frecuentes. Cabe resaltar en este ensayo el subapartado "El microrrelato vs. Todorov", en el cual se aborda la clasificación de este teórico sobre la literatura fantástica (las categorías 'fantástico', 'extraño', 'maravilloso', 'fantástico-extraño', 'fantástico-maravilloso') y explica, además de ejemplificar, claro está, cómo esta "llega a resultar insuficiente en relatos en los que la respuesta al hecho sobrenatural se ve interrumpida y desconocemos si se produce tal vacilación en el personaje" (2020: 108). Dicha vacilación refiere a la experimentada por el lector, relativa a las leyes de la realidad que rigen en el texto: se eligen leyes naturales conocidas, o bien otras desconocidas, para terminar por definir al texto como extraño o maravilloso, respectivamente. Así pues, se cuestionan esas fronteras clasificatorias, de manera que la minificción "tiene la posibilidad de reducir información al máximo, lo que permite evadir la clasificación por su manejo de la reacción y lo sobrenatural", y se agrega, "este rasgo merece ser analizado como una posibilidad específica del microrrelato: la elisión consciente de elementos tradicionalmente considerados constitutivos de los géneros relativos a lo sobrenatural, con intención de producir efectos particulares y específicos de esta forma narrativa" (2020: 109). La minificción, "al disponer de una amplia tolerancia a los vacíos de información, puede llevar el tratamiento de lo sobrenatural al extremo de la ambigüedad" (2020: 113).

En el "Epílogo", la autora, de acuerdo con lo expuesto en su investigación, comenta que "las características atribuidas a la minificción en estudios previos - humor, intertextualidad, uso de los títulos, tendencia hacia lo fantástico - resultaron, más bien, recursos que se privilegian en cada época, autor, proyecto, etcétera" (2020: 117). El libro cierra con una serie de entrevistas (listado que, comenta Rodríguez, planea ampliarlo en un futuro) con minificcionistas que también escriben crítica o ensayo: Agustín Cadena, Armando Alanís, José Juan Aboytia, Dina Grijalva, Édgar Omar Avilés y Fernando Sánchez Clelo, para abordar temas desarrollados en el libro, aunque también otros puntos, por ejemplo, qué consideran los entrevistados como necesario para la calidad en la escritura del género, las características y aportaciones de este, cómo se acercaron al mismo, o a cuáles autores consideran sus maestros. 
Permanente fugacidad es un libro que profundiza en el análisis de las características y elementos recurrentes de la minificción, al grado de concluir que estos no resultan definitorios sino de aparición parcial, con matices y finalidades muy variables, además de profundizar en el estudio teórico de temas estrechamente relacionados. El libro además señala derroteros interesantes en el estudio del género, como es el caso de lo ya planteado en el subapartado "El microrrelato vs. Todorov", así como también clarifica situaciones que en un primer momento parecerían no evidentes: los mecanismos de reiteración están presentes en el género, resultan necesarios, frecuentes y enriquecen la escritura, todo lo cual señala que no deben ser desechados en favor de la constante búsqueda de la brevedad, que en ocasiones pareciera tornarse en exceso. Obra analítica, de abundante bibliografía teórica y poblada de ejemplos, Permanente fugacidad actualiza el estudio de la minificción, clarifica situaciones que podrían hacer caer en el prejuicio y da voz y señala a los participantes de la comunidad minificcional en México.

Juan Carlos Gallegos

Universidad Autónoma Metropolitana-Unidad Iztapalapa jcgallegos.email@gmail.com

DOI: $\underline{\text { https://doi.org/10.24029/lejana.2022.15.3560 }}$

Recibido: el 2 de septiembre de 2021

Aceptado: el 16 de diciembre de 2021

Publicado: el 25 de febrero de 2022

(C) Juan Carlos Gallegos

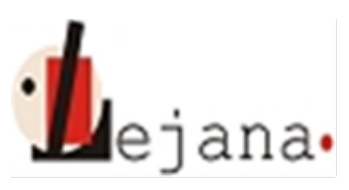

http://ojs.elte.hu/index.php/lejana

Universidad Eötvös Loránd, Departamento de Español, 1088 Budapest, Múzeum krt. 4/C 